\title{
Teacher Based Factors Influencing Academic Performance among Learners in Open Learning Classes at Twin Palm Secondary School, Lusaka, Zambia
}

\author{
Martha Siachifuwe* \\ Twin Palm Secondary School, Department of Social Sciences, Lusaka, Zambia
}

*Corresponding Author: Martha Siachifuwe, Twin Palm Secondary School, Department of Social Sciences, Lusaka, Zambia

\begin{abstract}
This study aimed at examining the influence of teacher related factor on pupils' academic performance in open learning classes at Twin palm secondary school in Lusaka district of Zambia and to establish measures to improve the academic performance of learners in open learning classes. It was prompted by the learners' general poor performance in class, termly assessments, the Junior Secondary School Leaving Examination and the General Certificate of Education Examinations.
\end{abstract}

The research targeted 118 pupils in Open Learning Class (OLC), 1 Head teacher, 1 Deputy Head teacher and 30 teachers offering different subjects at a particular school in Lusaka district. The 118 OLC pupils were grade Twelve, who were selected from different classes in the school since they had been in the school long enough to understand the factors that affect the learner achievement.

The study used purposive sampling. It employed qualitative data collection tools which included interview guides, a focus group discussion guide and observation. Only qualitative data collection tools were employed in order to ensure efficiency in data collection. Qualitative data was analyzed thematically.

The findings of the study revealed that the unsatisfactory academic performance of learners in Open Learning Classes was due to some of the teacher related factors such as, lack of teacher motivation, inadequate teacher preparedness, lack of punctuality by teachers, lack of teaching aids and non-marking of learners' exercises.

In line with the findings, the study made a number of recommendations to policy makers and school managers and these were:(i)Ministry of Education and school boards should find ways of motivating teachers and raising their morale,(iii) measures should be taken by school administrators to curb lack of punctuality among teachers who report late for work and (iii) MOE should increase supervision and carry out routine monitoring and evaluation of educational standards in Open learning classes for quality assurance by inspecting the teacher's lesson plan before delivering a lesson.

Keywords: Pupil, Open Leaning Classes, Teacher, Performance

\section{INTRODUCTION}

In this era of globalization and technological revolution, education is considered as a first step for every human activity. It plays a vital role in the development of human capital and is linked with an individual's well-being and opportunities for better living. It ensures the acquisition of knowledge and skills that enable individuals to increase their productivity and improve their quality of life. This increase in productivity also leads towards new sources of earning which enhances the economic growth of a country (Moola, 2015). The quality of students' performance remains a top concern for educators. It is meant for making a difference locally, regionally, nationally and globally. Educators, trainers and researchers have long been interested in exploring variables contributing effectively to quality of performance of learners. These variables that affect students' academic performance are both inside and outside the school. These factors may be termed as student factors, teacher factor, family factors, school factors and peer factors (Odumber et al, 2015).Teachers are facilitators of the learning process. They are unique in that they are architects, managers and engineers of pedagogy. This is why teaching and learning is central to any education system. The desire to provide education for all children is one of the major objects of the education system in Zambia. As such, the government of Zambia is currently implementing measures to improve the quality of education in 
secondary schools. Despite government measures like teacher salary increase to boost performance, performance in public schools in Lusaka district specifically has been persistently low. Studies done on the factors that influence pupil performance attest to the fact that there is a significant relationship between teacher based factors and pupil performance. Teachers play a critical role in the academic performance of the pupils. Teachers are indispensable elements in the teaching and learning process in most developing countries as they constitute the main agents of transmission of knowledge (Republic of Kenya, 2008). The factors affecting teachers in the performance of their duties affect the performance of the pupils. Therefore this study examined the teacher related factors that influence pupil performance in open learning classes. The factors examined were teacher motivation, teacher preparedness, marking of learners' exercises, punctuality of teachers and teacher teaching aid in class.

\section{AIM}

The aim of this study was to examine the influence of teacher related factor on pupils' academic performance in open learning classes at Twin palm secondary school in Lusaka district of Zambia and to establish measures to improve the academic performance of learners in Open Learning Classes.

\section{RESEARCH QUESTIONS}

The above aim was addressed through the following specific questions:

- What were the teacher related factors that influence pupil academic performance in OLC at Twin Palm Secondary school?

- What measures had been put in place to improve the performance of the learners in open learning classes?

\section{REVIEW OF LITERATURE}

Related literature consulted on this study revealed that there are some teacher related factors that affect pupil performance. The literature was reviewed under the following themes: inadequate teaching and learning aids, teacher-pupil ratio, lack of teacher competency, inadequate teacher prepare and teacher motivation.

a) Inadequate Teaching and Learning Aid: On the lack of enough textbooks, Mbozi (2008) in his study of quality of education in selected schools in Livingstone and Kazungula Districts in Zambia found that limited textbooks is a factor affecting academic performance of learners. According to his study, four classes of about sixty learners each shared only four textbooks amongst them, making it difficult for teachers to effectively use them during class lessons. Mbozi (2008:127) found limited textbooks as a factor affecting the performance of the learners. Researches done in Uganda and Ghana found significant effects leading the researchers to conclude that improving the availability of textbooks is of the most cost effective methods for enhancing learning achievement. While these findings cannot be disputed, the findings in Zambia slightly differ.

In Zambia, it was discovered that simply raising the number of books does not automatically improve learning outcomes and that teacher training must be improved in order to ensure effective teaching and use of textbooks (Kelly and Kanyika, 2000). In addition, the findings at Middle basic level revealed that performance improves when books are made available and that improvement only occurs when they are shared. According to the study, the highest achievement was observed when one book was shared between two learners. However, while this was the case in other subjects, achievement in Mathematics was found to be at its best when there were no textbooks for use at all. It was suggested, in the study, that it could be so because the teacher was the only resource available for the learners making him or her to actively endeavor to instill the necessary comprehension and elicit the desired procedures. This was said not be the case when books were available in that the teacher no longer sensed the need for vigorous teaching and simply allowed learners to make their way through texts, exercises and examples provided in books.

b) Teacher-Pupil Interaction: Mbozi (2008) allude to teacher-pupil interaction as a factor that affects academic performance of learners. By this he referred to situations where the teacher would use abusive language, threatens learners or shouts at them for various reasons. This resulted in the 
learners feeling out of place and inattentive in class due to fear or resentment for the teacher. Eventually such learners tended to abscond from school and perform poorly in the end .According to Molopo (2010),the proponent of the humanistic paradigm states that an individual has freedom and ability to attain self -development or self-learning and is capable of directing his or her own learning as long as the environment is enabling. Therefore, teachers are the custodians of the teaching and learning hence, they should take time to make their learners learn best and take keen interest in them, thereby achieving quality education delivery provided the teacher places the learner at the center of their teaching plan. In the researcher's view, this implies that the teacher must plan adequately every time, report for work on time, be resourceful and innovative as well as avoiding absconding classes. It can be argued that this high teacher-ratio could be experienced by teachers at Twin Palm Secondary school.

c) Lack of Teacher Competency: Globally, poor pupil academic performance is caused by so many factors as alluded above. Jazmawi (2008) suggested that the problem of poor academic is a global problem that any community is hardly devoid of it, that twenty pupils of every hundred have weakness in the academic achievement. Poor examination performance is caused chiefly by substandard quality of education background. The lack of teacher competence and not giving tests or examinations to the learners on a regular basis contributes to poor performance in academic work. It can be argued that this lack of competency could be portrayed by some teachers at Twin Palm Secondary school.

d) Inadequate Teacher Preparation: Some schools performed poorly because of teacher related factors such as, inadequate teacher preparation and teacher's lack of dedication to duty. Secondary school teachers were expected to prepare what they taught in schools. These preparations could be in form of schemes of work, records of work, and lesson plans to guide the teaching process (MOE, 2001).But it can be argued that teachers at Twin palm secondary school hardly prepared for their lessons hence affecting the academic performance of pupils in open learning centres

e) Motivation: Another factor is motivation. A highly motivated person puts in the maximum effort in his or her job. Several factors produce motivation and job satisfaction. Young (1988) examined the job satisfaction of Californian public school teachers in the USA and found that one of the overall job predictors was the salary one earned from it. Studies by Lockheed et al. (1991) indicated that lack of motivation and professional commitment produce poor attendance and unprofessional attitudes towards students which in turn affect the performance of students academically. This lack of motivation in teacher to perform their duties diligently could be manifested in teachers at the school in question.

\section{METHODOLOGY AND RESEARCH APPROACH}

This study used a case study design in order to unpack the research topic under investigation. It relied on the qualitative methods. Furthermore, this study used a combination of primary and secondary data in answering the research questions that were outlined. The study sample included 1 head teacher and 1 deputy head teacher and 30 class teachers of different subjects, since they had been in the school system long enough to understand the factors that affect the learner's achievement.

The study used purposive sampling. It employed qualitative data collection tools which included interview guides and a focus group discussion guide and observation. Only qualitative data collection tools were employed in order to ensure efficiency in data collection. Qualitative data was analyzed thematically.

\section{RESULTS AND DISCUSSION}

\subsection{Teacher Related Factors that Influence Academic Performance at Twin Palm Secondary School.}

Using the semi- structured interviews, this study sought to find out the teacher related factors that influenced pupil academic performance at Twin palm secondary school. According to the collected data, administrators and the teachers at Twin palm secondary school noted the following as the teacher related factors that influenced academic performance of learners: non marking of learner's exercises, lack of teaching aid, lack of motivation, ill preparedness of teachers, teacher abscondment and lack of punctuality. 
a) Lack of Teacher Motivation: According to the focus group discussions, it was noted that most teachers at the school lacked motivation from the administrators. There were no proper incentive structures from the administration and also the school had limited housing facilities for the teachers forcing the teachers to find their own accommodations in far places as the nearby residential areas fetched higher rentals that most teachers said they could not afford. Majority of the teachers interviewed agreed that the school administration did not organize motivational trips and treats even at least once annually. This led to ill preparedness of teachers in delivering lessons to Open Learning Classes and ultimately affecting the performance of pupils. This lack of teacher motivation was also noted by Musili (2015) in some research carried out in public secondary schools in kibwezi sub-county, Kenya. It was further observed that, when teachers are motivated, they are able to perform better, than when they are frustrated or ill motivated. A highly motivated teacher would go an extra mile in ensuring effective syllabus coverage. He or she also gives extra work to the weaker learners, and this will certainly ensure improved school performance. Extra work given to students can positively influence their performance and it enables students to effectively complete the syllabus thus giving room for revision (Cowell \&Holsinger, 2000).

b) Lack of Punctuality by Teachers: Another teacher related factor viewed in the study was teacher punctuality. It came out during the interviews with head teachers that some teachers were fond of going late for classes. As a result of lack of punctuality, they tended to rush through the lessons to cover up for lost time. By so doing, the slower learners failed to grasp the concepts and lagged behind. Moreover, teachers rushing through their lessons impacts negatively on pupils' comprehension of the taught material or the teacher's failure to complete their planned work which disadvantages the learners thereby adversely affecting their academic performance. Teachers' punctuality to work is a vital factor or sub-variable of teachers' attitude to work, which can affect academic performance of pupils, Teachers who are always punctual to school can instill such attitude in pupils and this can result in good academic performance of the pupils. According to Alexander (2003), by the Guyana law, teachers require to report for duty at least fifteen minutes before the start of lessons each day in order to prepare and to be ready to start work promptly.

c) Non Marking of Learners 'Exercise: Observations and interactions with both teachers and pupils revealed that there was a perception that only very few teachers marked the pupils' exercises. Class exercises serve as a form of assessment of the learners' progress and as feedback for the teacher to discover whether the lesson objectives had been met or not. This non marking of pupils' exercise was also noted by Molokomphale and Mavis (2014) in their study carried out in Junior Secondary Schools in Botswana. If the teacher gives class exercises and does not mark them afterwards, then it will be very difficult for the teacher to know if the pupils have understood the lesson or not. This is seen as laissez-faire attitude or lack of commitment towards duty on the side of some of the teachers. This results in poor academic performance in the pupils

d) Insufficient Preparation of Teachers: Teacher preparation such as writing schemes, records of work and lesson-planning is a professional requirement for teachers in Zambia (Malambo, 2012). However, the study revealed the lack of adequate lesson preparation on the part of teachers as another factor affecting pupilse academic performance. Ultimately this insufficient preparation robs the learners of quality learning because the teachers would not be able to deliver quality lessons as required of them. As one member bemoaned;

"If one has not adequately prepared, it's difficult for them to deliver effectively as some valuable aspects of the lesson which may have benefitted the learner may be omitted and thereby denying the learner of essential knowledge."

e) Lack of Teaching or Learning Aids: The study revealed the non-availability of teaching or learning aids at the school and this hinders teachers to deliver as expected hence affecting the learners' academic performance. This is an impediment to teachers to deliver as expectedly affecting the comprehension of the subject matter by the learners.

\subsection{Measures to Improve the Performance of the Learners in Open Learning Classes}

The study revealed that there were measures that could enhance performance of the learners in open learning classes. These measures came out from the interviews with the Head teacher, Deputy Head 
and some focus group discussions with teachers across different subjects. It was interesting to note that most responses where oriented towards improving internal systems that guided and managed the operation of the school. The following measures came out vividly from the research;

- Management of the school under the study needed to put up motivation incentive or reward structures in order to strengthen, keep and improve the morale of the teachers. For example, Individual recognition of high performing teachers. It is undeniable that a motivated staff keeps pushing for better and enhanced ways to improve their performance and ultimately produce good results at learner's level. In addition to the motivation for teachers, there was need of putting up attractive incentives for high performing learners, for example; prize giving

- The study revealed that it was imperative that management of the school in question could put up strong preventive measures to poor performing teachers .for example, checking in advance lesson plans before delivering of lessons to the learners by the teacher

- Management could put up deliberate and robust strategy to facilitate the stocking of the library with adequate textbooks and reading material to improve the reading culture of the pupils and access to relevant information

- The school management should strongly take up the login-logout register for the teachers to deal with the teachers that report late for work and go to class late.

- Receive in-service training and professional development within the profession in order to motivate them

- The school should rob for more financial resources by conducting more fundraising ventures and accounting for the resources raised so that more teaching and learning aids could be bought for different subjects

\section{CONCLUSION}

There are a number of various factors inside and outside the school that influence the quality of academic performance of pupils in open learning classes. However, this study only focused on some of the teacher related factors within school that influence the student's achievement scores. The key aspect for the educators is to educate their students effectively so that they may be able to show quality performance in their academics. To achieve this objective, it is necessary for the educators to understand the factors that may contribute to the academic success of pupils. The following are the findings which the researcher made of this study. The pupils' poor academic performance in continuing education schools was a result of lack of teacher motivation from school management, lack of teaching and learning aids, ill preparedness of teachers, non-marking of learner's exercises and lack of punctuality on the part of teachers.

\section{REFERENCES}

[1] Alexander. W.(2003). Attendance and Punctuality. Retrieved on 1/11/2017.from http://www.education.gov.gg

[2] Cowell R.N \&Holsinger D.B (2000). Positioning Secondary School Education in Developing Countries.Paris:UNESCO, IIEP.

[3] Jazmawi, A. (2008).Underachievement and Low Success Rate of Jordanian Students in Secondary Schools. Arab Open University. Jordan.

[4] Kelly, M.J. and Kanyika, J (2000) Achievements of the Middle Basic Level: Final Report on Zambia's National Assessment Project: Lusaka Ministry of Education.

[5] Molokomphale. L and Mavis, B.M (2014), Investigation on Students Academic Performance for Junior Secondary Schools in Botswana. European Journal of Educational Research.Vol.3, 111-127

[6] Malabo, B. (2012) Factors Affecting Academic Performance of Grant-Aided and Non - Grant Aided Secondary Schools: A Case of Selected Secondary Schools in the Western Province of Zambia. A Master of Education Thesis: University of Zambia.

[7] Mbozi, E.M. (2008) Classroom Factors that affect the quality of Education in selected Basic Schools in Livingstone and Kazungula Districts in Southern Province in Zambia. A Doctorate Dissertation. Lusaka: The University of Zambia, Unpublished. 
[8] Mulopo, M. (2010). Stakeholders" Perception of Factors affecting The Performance of Open Secondary School classes: A case of one Open Secondary School Centre in Mazabuka, Zambia. Master of Education Thesis. Lusaka: The University of Zambia.

[9] Ministry of Education (2001),General Certificate of Education Results Analysis Report. Lusaka

[10] Moola, I. (2015). Factors affecting academic performance of learners in continuing education schools: a case of central, southern and western provinces of Zambia. Masters of Education Thesis. Lusaka: The University of Zambia, Unpublished.

[11] Musili A.M, (2015), Influence of teacher related factors of students' performance in Kenya certificate of Secondary education in public Secondary schools in Kibwezi sub-county. Kenya. Masters of Education Thesis. South Eastern Kenya University.

[12] Odumber G A, Enose MWS and Ayedo TMO (2015).Factors Influencing Student Academic Performance in Day Secondary Schools in Kenya. Case Study of Magori Sub County. Greener Journal of Education Research, 5(3):078-097.

[13] Republic of Kenya (2008), First Medium Term Plan (2008-2012), Kenya Vision 2030,A Globally Competition and Prosperous Kenya,Nairobi:Government Printer.

\section{AUTHOR'S BIOGRAPHY}

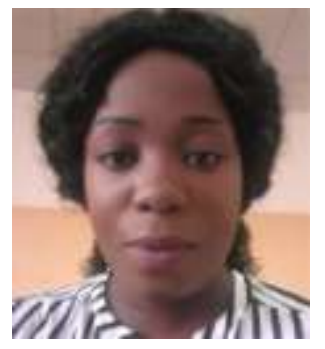

Martha Siachifuwe, was Born in 1988 in Livingstone, She Acquired a bachelors of Arts degree with merit from the University of Zambia in 2012, with a major in geography and she obtained a masters of education in education management in 2017.

Currently she is working as a Geography secondary school teacher at Twin palm secondary school. Lusaka Also she is the head of section in the Geography department under social sciences department.

Citation: Martha Siachifuwe "Teacher Based Factors Influencing Academic Performance among Learners in Open Learning Classes at Twin Palm Secondary School, Lusaka, Zambia" International Journal of Humanities Social Sciences and Education (IJHSSE), vol 4, no. 12, 2017, pp. 96-101 doi: http://dx.doi.org/10.20431/2349-0381.0412012.

Copyright: (C) 2017 Authors. This is an open-access article distributed under the terms of the Creative Commons Attribution License, which permits unrestricted use, distribution, and reproduction in any medium, provided the original author and source are credited. 